\title{
Methods Of Evaluating Noise Pollution IN THE MEGALOPOLIS
}

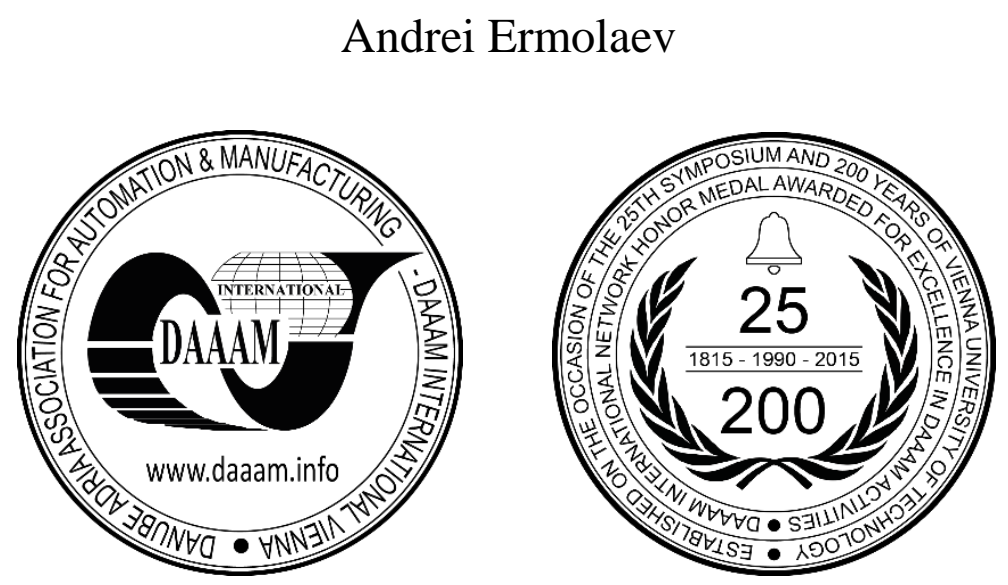

This Publication has to be referred as: Ermolaev, A[ndrei] (2017). Methods Of Evaluating Noise Pollution In The Megalopolis, Proceedings of the 28th DAAAM International Symposium, pp.0926-0929, B. Katalinic (Ed.), Published by DAAAM International, ISBN 978-3-902734-11-2, ISSN 1726-9679, Vienna, Austria DOI: $10.2507 / 28$ th.daaam.proceedings. 128

\begin{abstract}
The purpose of the research is to build an effective system for assessing noise pollution during sports events in residential areas of the megalopolis. A combination of methods is proposed - measuring the level of noise pollution using a sound meter and analyzing the complaints of local residents. The influence of noise on the humans is estimated. Investigation of noise pollution near two sports grounds in residential areas of Moscow has been carried out. Methods for reducing noise are proposed. Conclusions about the effectiveness of the proposed system of assessments are made and ways of its improvement are proposed.
\end{abstract}

Keywords: environment; urbanization; noise pollution; assessment system

\section{Introduction}

The state of environment in the modern world is directly related to the degree of development of social consciousness as well as to the understanding of relationship between the nature and a human being.

Ecological monitoring is the system designed for observing, gathering and storing of information related to the state of environment, well-targeted environmental assessment of such information, forecasting the state of environment taken in conjunction with natural and anthropogenic factors. The purpose of ecological monitoring can be described as obtaining reliable information concerning the state of environment, data processing, forecasting changes in the state of environment, and assessment of mutual influence between the environment and a man [1]. The most observable (whether in a negative or in a positive way) mutual influence can be assessed using the example of living in megalopolis, where large gatherings of people structure their interactions with the environment.

Moscow is the largest city of Russia (as of 2017, it has a population of more than 12300000 citizens), the center of the economic life [Federal State Statistics Service - www.moscow.gks.ru]. Moscow is the center of the ringed structure of transport routes in the European part of Russia, which provides for additional increase of traffic in the city. These factors always result in the increased noise pollution level in Moscow. The additional factor contributing to the noise in residential areas is the holding of sports events. 
The topicality of the research lies in the fact that noise pollution problem is oftentimes ignored, although it has an influence on the second most significant sensory receptor of humans - the sense of hearing.

The purpose of this study is to build an effective system for evaluation of the influence on noise pollution caused by placing sports fields in the city's residential districts. In this study, the following methods are discussed:

1. Measuring noise pollution level;

2. Analyzing the complaints of local residents posted on municipal information portals.

\section{Effect of noise pollution on humans}

Noise pollution is the excess of natural background noise level or abnormal change of sound characteristics: rate of recurrence, sound volume, etc. Noise pollution is among the three most significant ecological disturbances in the world. Along with the growth of urbanization, noise became a permanent part of human life and one of the major parametric pollutants of the urban environment. The problem of protection of population against the excessive noise is primarily a healthcare issue [2].

Today, it is acknowledged that noise is a common biological irritant, i.e. it has an influence not only on the organs of hearing, but on the entire organism as well. First of all, noise affects cerebral structures, which leads to adverse changes in the functioning of various organs and systems. The central nervous system is the most sensitive to the impact of such noise levels. Its first reaction to the impact of noise is the change of its functional status indicators. People affected by noise most typically complain of headaches, which may vary in terms of amount and distribution, dizziness after a postural change, hypomnesia, undue fatigability, somnolence, sleep disturbances, emotional instability, loss of appetite, hyperhidrosis, chest pain [2][7].

Noise is one of the strongest factors of stress. Noise has an impact on the functions of endocrine and immune systems of the body, which may manifest itself, in particular, as three main biological effects [3]:

- Decrease in immunity to infections;

- Decrease in immunity to the development of neoplastic processes;

- Presence of a conducive environment for the emergence and development of allergic and autoimmune processes.

The impact of noise on the organism is quite complex and should be avoided. This is the reason why measures for improvement of personal environment with the purpose of protecting it against the noise factor are essential for the modern society of technology and urbanization.

\section{Methods of studying noise pollution in residential areas of Moscow}

According to Russian standards, the following noise requirements are set for residential premises: - maximum sound level during the daytime (from 7 AM to $11 \mathrm{PM}$ ) - no more than $55 \mathrm{~dB}$;

- maximum sound level during the nighttime (from $23 \mathrm{PM}$ to $7 \mathrm{AM}$ ) - no more than $40 \mathrm{~dB}$.

Therefore, the level of noise in residential premises must not exceed the volume level of a calm conversation [4].

\subsection{Method of measurement of noise pollution level}

In September 2017, measurements of the noise level were performed in the districts of Moscow. The measurements were performed on $17^{\text {th }}$ and $18^{\text {th }}$ of September in the area of Geroev-Panfilovtsev str. 1-5 (Point $\mathbf{A}$ ):

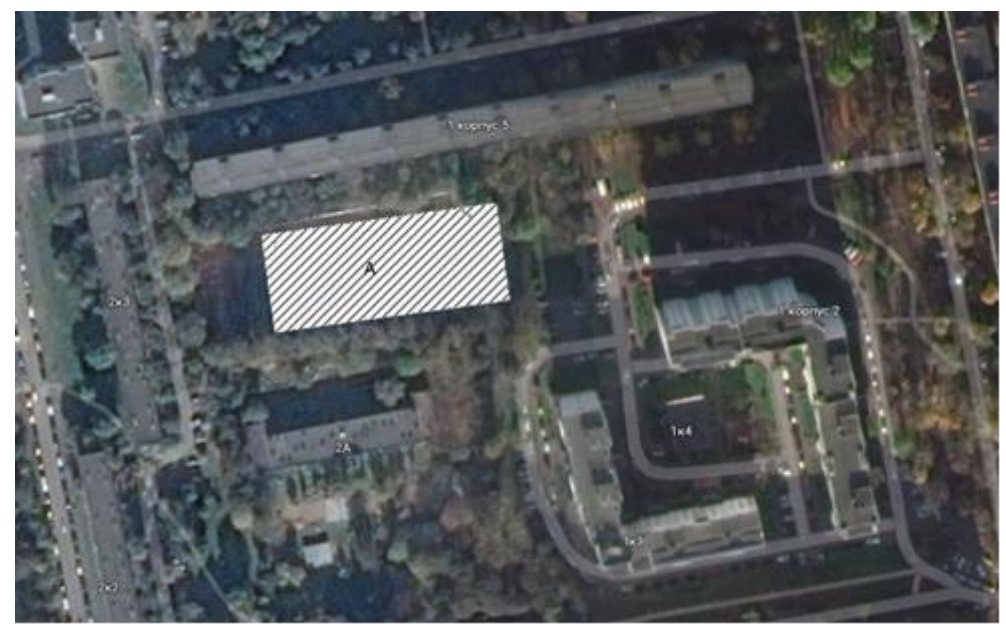

Fig. 1. Point A 
and on $24^{\text {th }}$ and $25^{\text {th }}$ of September in the area of Shirokaya str. 9 (Point B):

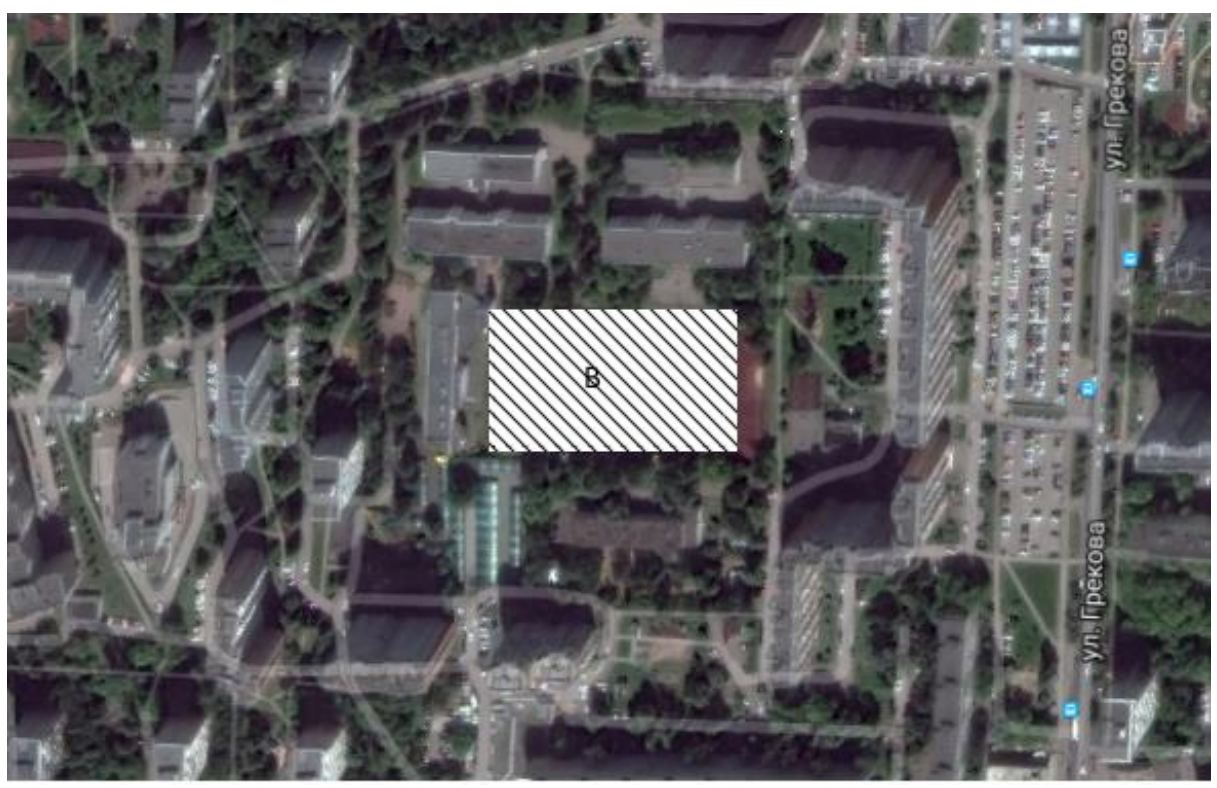

Fig. 2. Point B

In point $\mathrm{A}$, the distance from the sports field to the nearest residential building is 18 meters, in point $\mathrm{B}-22$ meters. The measurements were taken from 3 to $11 \mathrm{PM}$ under normal conditions and during sports events. "Digital Sound Meter AR854" device was used. The measurement results are given in Table 1 and Figure 1:

\begin{tabular}{|c|c|c|c|c|c|}
\hline Point & $\begin{array}{c}\text { Maximum } \\
\text { permitted value, } \\
\mathrm{dB}\end{array}$ & $\begin{array}{c}\text { Maximum } \\
\text { values when } \\
\text { measuring under } \\
\text { normal } \\
\text { conditions, } \mathrm{dB}\end{array}$ & $\begin{array}{c}\text { The value of } \\
\text { violation of } \\
\text { sanitary standards } \\
\text { under normal } \\
\text { conditions, dB }\end{array}$ & $\begin{array}{c}\text { Maximum values } \\
\text { when measuring } \\
\text { during sports events, } \\
\mathrm{dB}\end{array}$ & $\begin{array}{c}\text { The value of } \\
\text { violation of sanitary } \\
\text { standards during } \\
\text { sports events, dB }\end{array}$ \\
\cline { 1 - 5 } A & \multirow{2}{*}{$\mathbf{5 5}$} & 74 & 19 & 87 & 32 \\
\cline { 1 - 5 } & & 78 & 23 & 90 & 35 \\
\hline
\end{tabular}

Table 1. Measurement results.

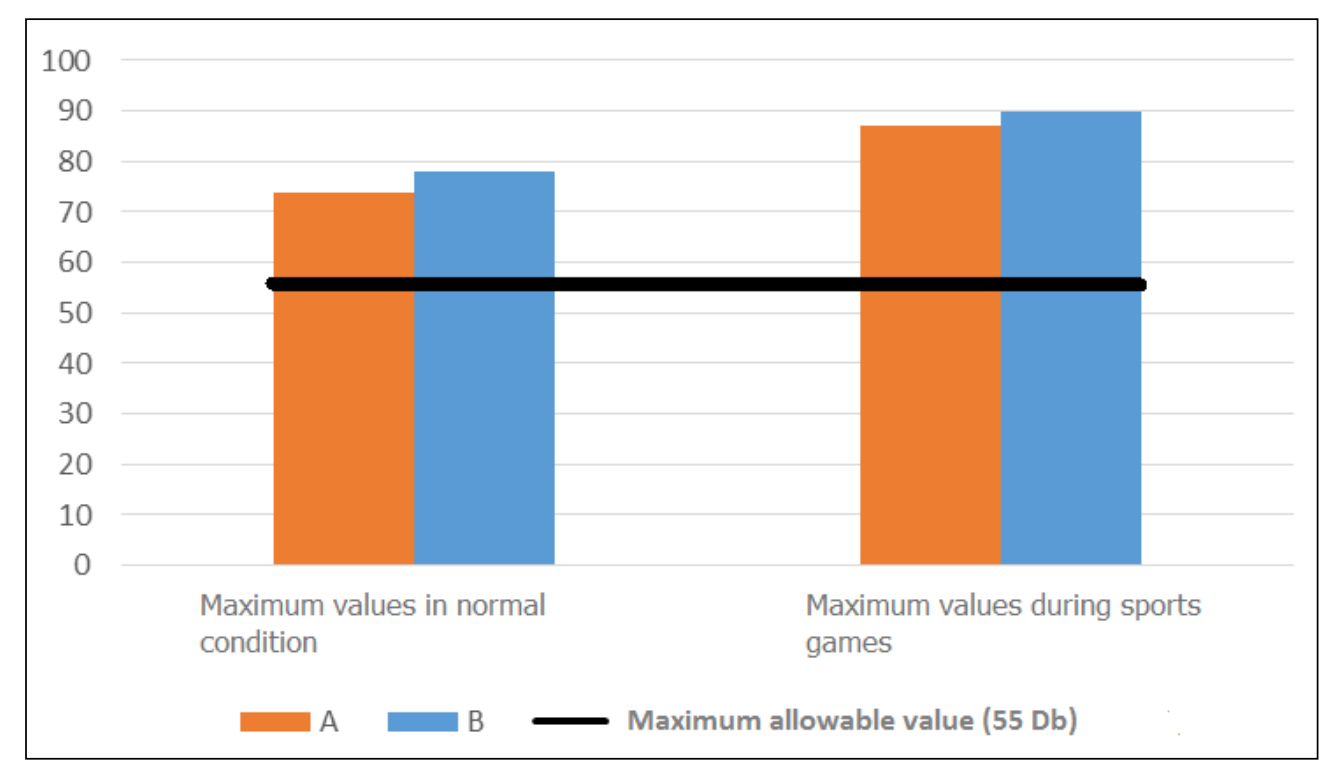

Fig. 3. Correlation of noise level measurements in points A and B. 


\subsection{Method of analyzing complaints of local residents}

This method involved the analysis of municipal public information portal "Active Citizen", the purposes of which include submission of complaints by, and control over administration of complaints given by, the citizens. Search of complaints submitted with the indication of a residential address adjacent to the sports fields in point A or B has shown low efficiency of this method. Thus, there is only one complaint per 700 citizens who live in the houses located near points $\mathrm{A}$ and $\mathrm{B}$ [5]. Among the factors reducing the efficiency of this method, we can mention that the user must have a certain level of computer skills in order to register and submit a complaint. We must note that citizens don't have no way of objection evaluation of the degree of impact of noise pollution on their health, and taking account of the passivity in solving secondary problems which is peculiar to the most of people, they usually don't give due consideration to it.

\section{Methods of noise level reduction}

Currently, most of sports fields are built without the use of sound insulation materials, which leads to high values of impact noise during sports events (from ball slams, etc.). Thus, the level of impact noise from the ball slamming against the banking board of the sports field in points $\mathrm{A}$ and $\mathrm{B}$ at the 20 meters distance is equal to $82 \mathrm{~dB}$. This value significantly exceeds the permitted value, so it is necessary to use sound insulation materials and structures. Modern industry offers a variety of options. For example, cork rolls are able to reduce the impact noise level by $12 \mathrm{~dB}$ [6]. Multilayered structures are the most efficient: using combinations of various materials, it is possible to reduce the impact noise level during sports events to the permitted values. For protection of the upper floors, it is reasonable to use noise screens.

The alternative way is the use of vegetation plantations around the sports fields as a natural noise-absorbing material. In addition, this would allow improving the ecological and aesthetical aspects of the residential area.

The other method of reducing noise pollution is to place the sports fields at such a distance from residential buildings that the sound wave would disperse before reaching them. Oftentimes, one can observe violations of design and planning standards for placement of sports fields against residential buildings, which lead to the increase of noise pollution.

\section{Conclusion}

As a result of the study performed, the following conclusion should be made about the effectiveness of the proposed system for assessing noise pollution during sporting events in the residential neighborhoods of the megalopolis. The method of estimation by a sound meter proved to be effective, but requires a systematic approach and regular implementation with the maintenance of a citywide measurement base, that allows estimating changes in indicators over a long period. The assessment method of analyzing complaints of local residents proved ineffective due to the poor awareness of the residents about the negative impact of the increased noise level, which indicates that the problem is undervalued. The main problem is the lack of public objective data and discussions in the society.

To improve the effectiveness of the evaluation system I propose to supplement it by statistical information from health organizations. Thus, it will be possible to monitor the effect of noise pollution on local residents without regular measurements of the level of noise pollution. According to the statistics of residents' complaints, which are a consequence of the influence of the increased noise level, it is possible to identify areas with increased noise level and to carry out the necessary work to eliminate noise pollution by constructing sound insulation structures or reconstructing objects that are sources of noise.

\section{References}

[1] A.V. Shamraev (2014). Environmental monitoring and assessment: teaching medium, Federal State Budgetary Institution of Higher Education "Orenburg State University". - Orenburg: OSU, 2014, ISBN 978-5-905383-37-3

[2] V.V. Minaeva; A.V. Gaponenko (2015). "The impact of noise on a human organism", International students' science bulletin, 2015 - No. 3 (part 1), pp. 56-58, ISSN 2409-529X

[3] S.V. Alekseev, Yu.P. Pivovarov, O.I. Yanushanets. (2002) Human ecology: Textbook. - M.: Ikar,. ISBN 5-79740054-5

[4] GOST 12.1.003-2014. Occupational safety standards system "Noise. General safety requirements", SN 2.2.4/2.1.8.562-96 "Noise at Workplaces, in Residential and Public Spaces, and in Areas of Residential Development"

[5] Portal "Active Citizen", https://ag.mos.ru/info

[6] Gruppa7 website, http://gruppa7.ru/articles/27/

[7] Hoffmann, Barbara; Moebus, Susanne; Stang, Andreas; Beck, Eva-Maria; Dragano, Nico; Möhlenkamp, Stephan; Schmermund, Axel; Memmesheimer, Michael; Mann, Klaus (2006-11-01). "Residence close to high traffic and prevalence of coronary heart disease". European Heart Journal. 27 (22): 2696-2702. ISSN 0195-668X 